\title{
POST-THYROIDECTOMY VOCAL CORDS PARALYSIS DESPISTE NORMAL \\ INTRAOPERATIVE NEUROMONITORING OF THE LARYNGEAL NERVES DURING SURGERY
}

\author{
Batalla A., Cueva L., Castrillon S., Moreno M., Moral M.V. \\ Hospital de la Santa Creu i Sant Pau. Barcelona
}

\section{Background}

Recurrent laryngeal nerve (RLN) injury is one of the most common complications of thyroid surgery, affecting the patient's voice and the quality of life. Incidence of bilateral recurrent laryngeal nerve injury in total thyroidectomy oscillate between $5 \%$ without intraoperative neuromonitoring (IONM) to $2,4 \%$ with it.

\section{Case Report}

Female, 71 years old, undergoing total thyroidectomy for multinodular goitre. Intubation wiht NIM tube (fig. 1) was performed with videolaringoscope to ensure it's perfect location (fig. 2). No injury of the RLN were observed. She was extubed in the OR successfully.

The day after surgery, she started with progressive dysphagia. Hours later she presented dysphonia and stridor. ENT performed a nasal fibrobronchoscopy that showed "bilateral paresis of vocal cords with important reduction of the air flow, but conserved". (fig. 3)

We intensify medical treatment with adrenaline nebulisations. The symptoms slowly disappeared en 2-3 days.

Fig. 2

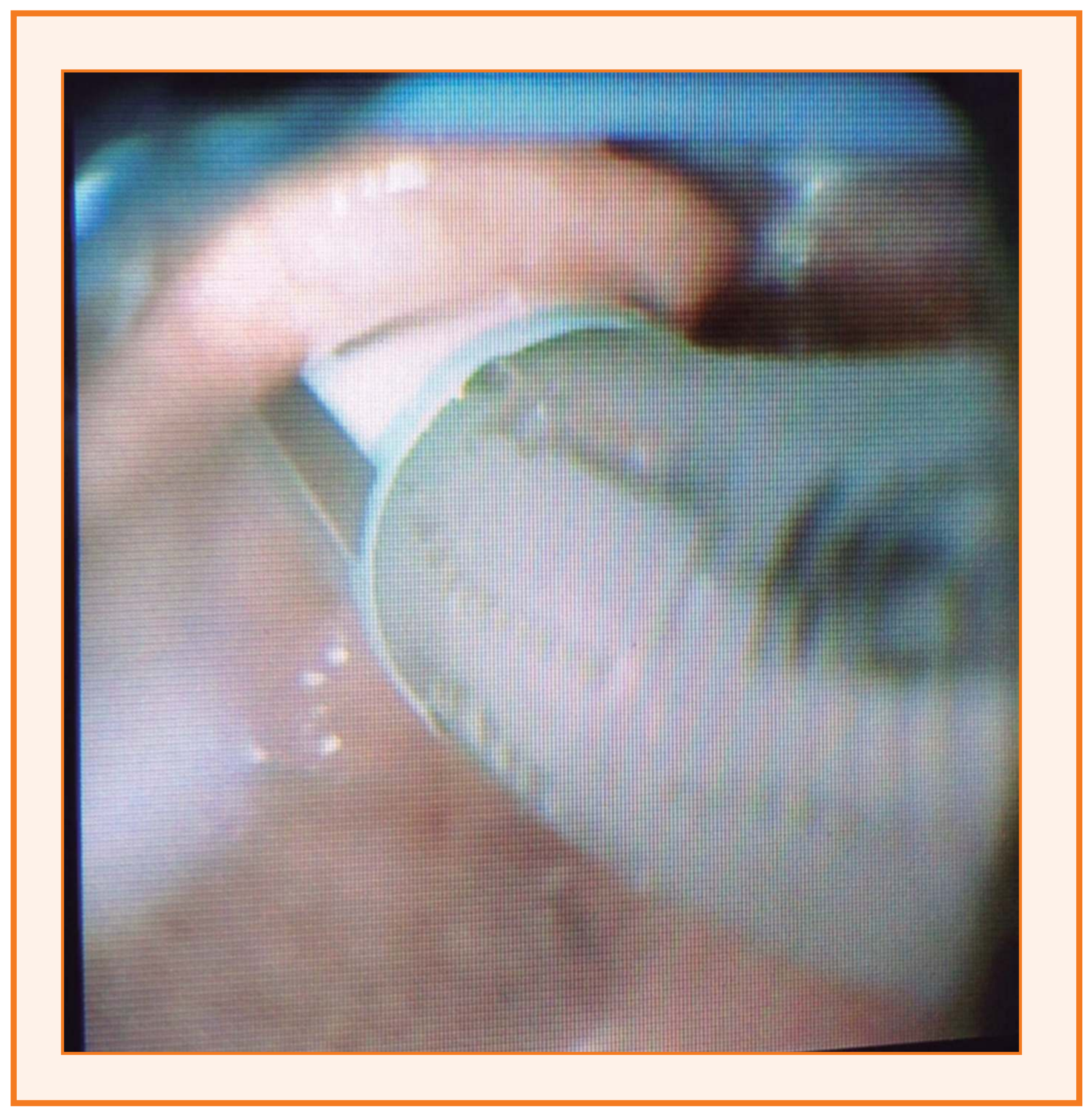

Fig. 3

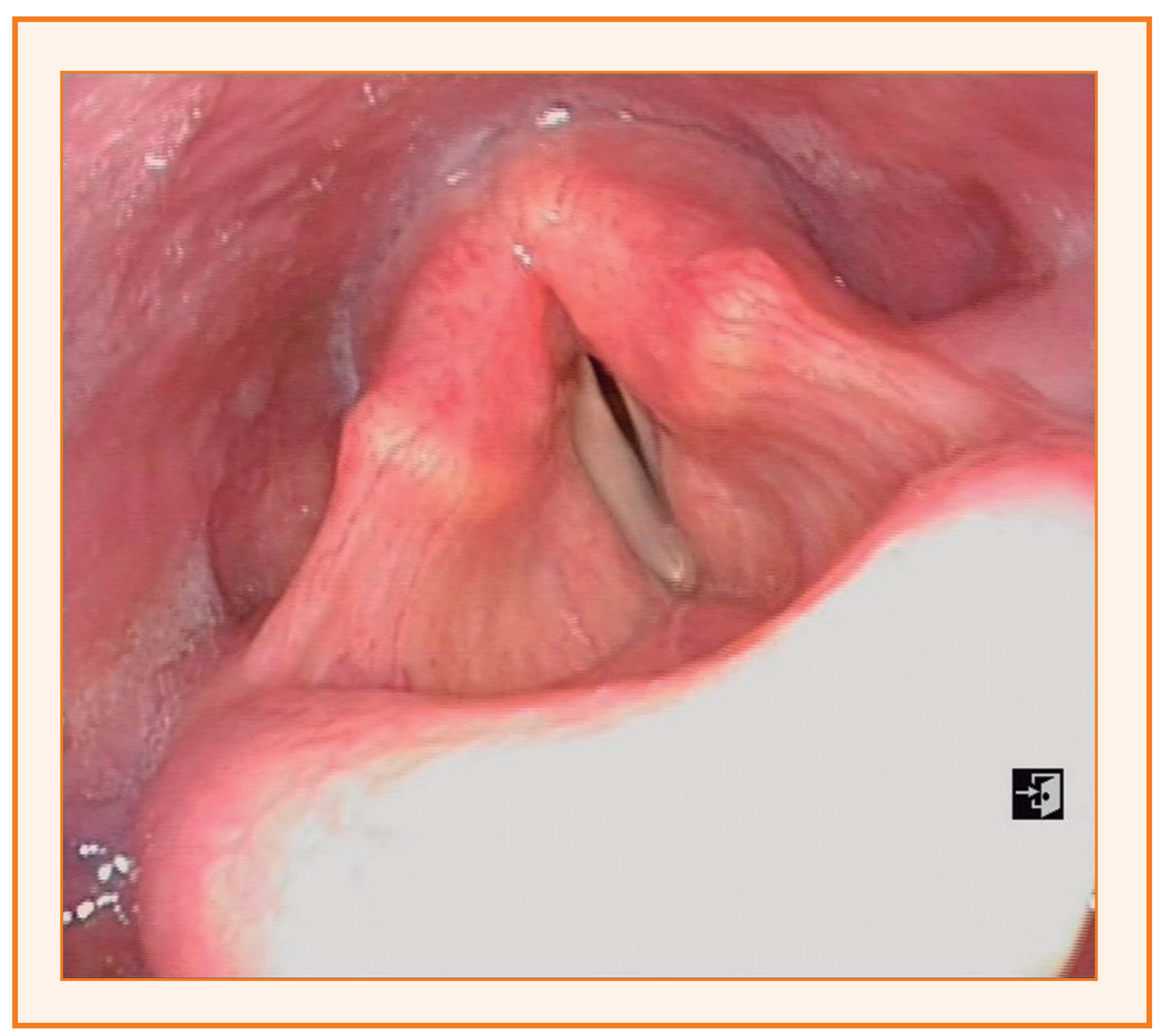

Fig. 1

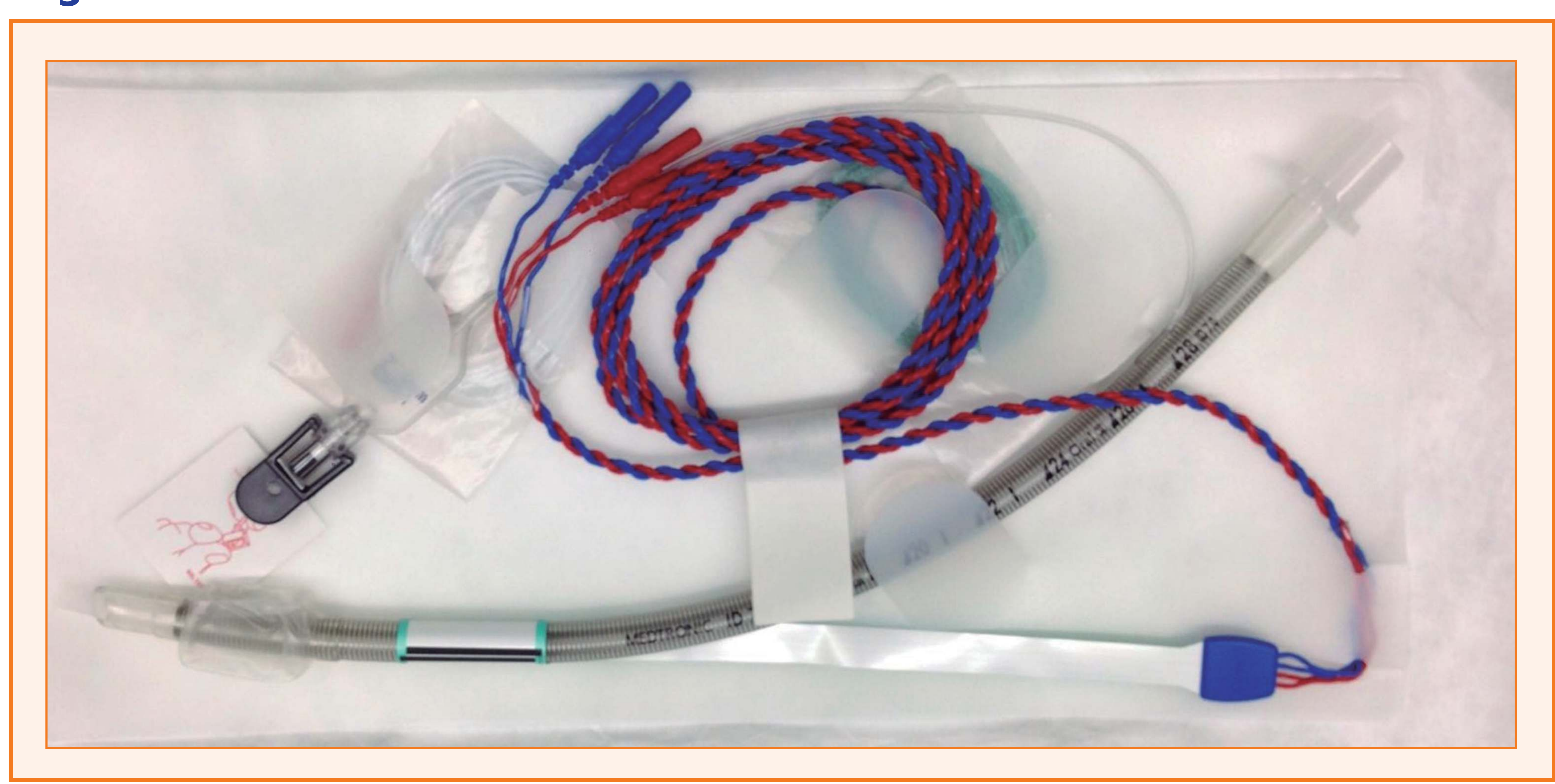

Fig. 4

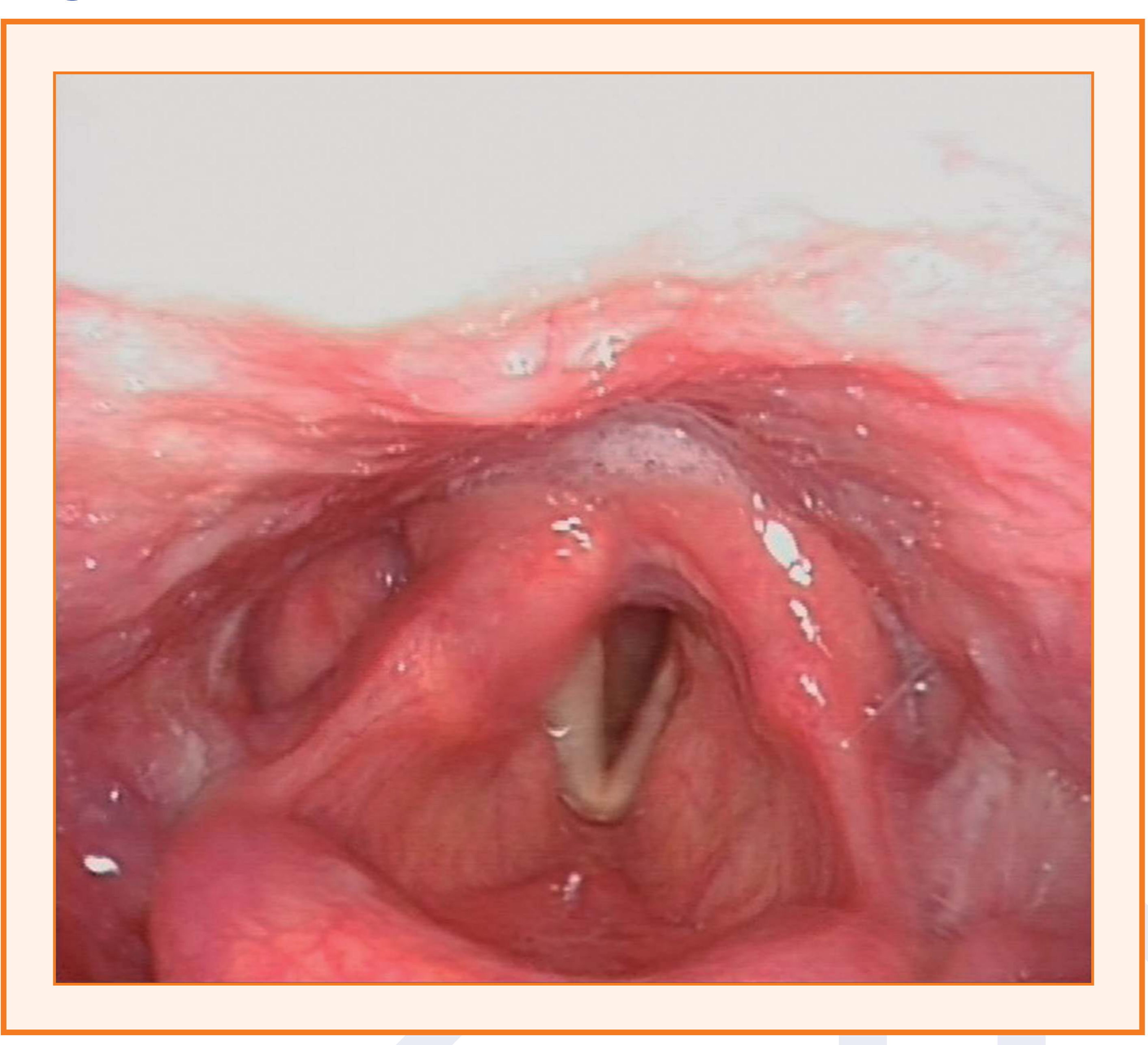

\section{Discussion and Learning points}

- The vocal cords paralysis is an important postoperative complication.

- It can occur even we have IONM.

- The key is to make an early diagnosis and set up treatment.

\section{References}

1- Deniwar A, Kandil E, Randolph G. Electrophysiological neural monitoring of the laryngeal nerves in thyroid surgery: review of the current literature. Gland Surg 2015;4(5):368-375. doi: 10.3978/j.issn.2227684X.2015.04.04

2- Pardal-Refoyo JL1, Ochoa-Sangrador C2. Bilateral recurrent laryngeal nerve injury in total thyroidectomy with or without intraoperative neuromonitoring. Systematic review and meta-analysis. Acta Otorrinolaringol Esp. 2016 Mar-Apr;67(2):66-74. doi: 10.1016/j.otorri.2015.02.001. Epub 2015 May 27. 